\title{
ADVANCES AND APPLICATIONS OF RENEWABLE ENERGY
}

\author{
Hussam Jouhara ${ }^{1^{*}}$, Luca Montorsi ${ }^{2}$, Marderos Ara Sayegh $^{3}$
}

\section{Scientific areas of this special issue}

This special edition of Renewable Energy is devoted to Renewable Technologies. For many years, measurements have clearly shown that global temperatures are rising, and extreme weather events linked to climate change are being observed ever more frequently. There is therefore a need for an increased and widespread employment of renewable technologies, not in a token or piecemeal way, in order to decarbonise the world's economy.

The very differing papers in this special edition reflect the wide range of research currently being conducted on the application of renewable energy resources. A number of them are highly relevant to the hydrogen economy and transport, given the worldwide desire to phase out vehicles using internal combustion engines. Underground energy is investigated for both deep level sources (geothermal energy) and shallow layers (for heat pumps operating with a heat source much closer to the surface). Wind energy and biofuels are topics for research with novel approaches for utilisation. In some cases, hybrid systems are proposed, rather than a technology based on a single renewable energy resource, and energy savings via recycling are also investigated. Finally, research is reported on a new approach for exploiting marine energy, a resource for which, despite decades of research, there is no optimised or even effective technology for large-scale energy extraction.

\section{Hydrogen economy and transport}

Hydrogen is seen as a promising carbon-neutral fuel, but to be of benefit it has to be generated in a carbon-neutral way. Conventionally hydrogen is separated for water using electrolysis; De Silva et al. [1] have investigated electrolysis using renewable energy and reported how the process can be enhanced. A different approach to hydrogen production was investigated by Pini et al. [2]. They examined the combined production of hydrogen and power based on the combustion of aluminium with water. Hydrogen can be used as a fuel in its own right or may be used in fuel cells. Cannio et al. [3] have employed the Additive Manufacturing Method (or 3-D printing) to manufacture fuel cells.

There is a link between fuel cells and transport since fuel cells can replace batteries as a power source, if vehicles using internal combustion engines are to be replaced with electric vehicles. Most electric vehicles have batteries as the power source and this raises the issue of the inevitable reduction in vehicle range when heating systems have to be employed. Recognising this, Ding et al. [4] have examined multiple heat sources for heating systems. Research of a different kind to reduce vehicle emissions has been conducted by Pirola et al. [5]. The authors report that the use of humidified oxygen-enriched air can increase the efficiency of a turbocharged diesel engine and reduce soot emissions.

\footnotetext{
*Corresponding Author: Hussam.Jouhara@brunel.ac.uk (Managing Guest Editor)

${ }^{1}$ Heat Pipe and Thermal Management Research Group, College of Engineering, Design and Physical Sciences, Brunel University London, UB8 3PH, UK

${ }^{2}$ University of Modena and Reggio Emilia, Department of Science and Methods for Engineering, 42122, Reggio Emilia, Italy.

${ }^{3}$ Faculty of Environmental Engineering, Wroclaw University of Science and Technology, ul. Norwida 4/6, 50-337 Wroclaw, Poland
} 


\section{Underground heat sources}

Bryś et al. [6] have conducted a very extensive study of heat fluxes in shallow soil layers, which can be utilised as the heat source in heat pumps, and have examined the influence of soil cover (for example, a bare soil surface or a grassy surface) on the results. Underground energy from greater depths can be achieved from geothermal sources, but Olabi et al. [7] note that geothermal energy extraction tends to be rather modest. To counteract this characteristic, the authors propose hybrid systems with geothermal energy coupled with other energy sources.

\section{Wind energy}

Wind energy is one of the most widely exploited renewable resources worldwide, but wind energy is a non-guaranteed supply and the minute-to-minute variations can have implications for the stability of the electrical grid. Faroog et al. [8] examined different approaches to control and concluded that fuzzy logic controllers offer the best performance. Wind energy on a much smaller scale has been investigated by Nduku at al. [9] for drying food products. This is an example of hybrid systems, because wind power was combined with solar energy and thermal storage.

\section{Biofuels}

Energy from waste is a win-win process, because not only are fuels and power generation obtained, the quantity of waste for disposal is also reduced. Two new sources of biofuels are described in this special edition. In the first paper, Kamil et al. [10] assess the economic, technical and environmental viability of diesel fuel derived from coffee waste. In the second, Afif et al. [11] examine the potential of biochar obtained from the pyrolysis of cotton stalks.

\section{Other papers}

Numerous technologies have been proposed to date for exploiting the motion of the sea, but no established design has emerged for marine energy extraction. One of the more recent design concepts is a tethered underwater sea kite, on which a turbine can be mounted for power generation. Liu et al. [12] have investigated the motion of such a device both experimentally and theoretically and found good agreement between their model and experimental data.

The two remaining papers could be listed under the heading of environmental gains in renewable energy processes. The first paper by Kim et al. [13] evaluates the possible reuse of wastewater arising from the alkaline treatment of a biofuel. In the second paper by Hsaio et al. [14] photovoltaic devices are used for harvesting artificial light for the operation of low power electronic devices.

\section{References}

1. Y. Sanath K. De Silva, Peter Hugh Middleton, Mohan Lal Kolhe, Performance comparison of mono-polar and bi-polar configurations of alkaline electrolysis stack through 3-D modelling and experimental fabrication, Renewable Energy 149 (2020) 760-772. https://doi.org/10.1016/j.renene.2019.12.087

2. Martina Pini, Giovanni Breglia, Matteo Venturelli, Luca Montorsi, Massimo Milani, Paolo Neri, Anna Maria Ferrari, Life cycle assessment of an innovative cogeneration system based on the aluminum combustion with water, Renewable Energy 154 (2020) 532-541. https://doi.org/10.1016/j.renene.2020.03.046

3. Maria Cannio, Stefania Righi, Paolo E. Santangelo, Marcello Romagnoli, Rolando Pedicini, Alessandra Carbone, Irene Gatto, Smart catalyst deposition by 3D printing for Polymer Electrolyte Membrane Fuel Cell manufacturing, Renewable Energy 163 (2021) 414-422.4. https://doi.org/10.1016/j.renene.2020.08.064

4. Peng Ding, Zhong Wang, Ying Wang, Kaiyun Li, A distributed multiple-heat source staged heating method in an electric vehicle, Renewable Energy 150 (2020) 1010-1018. 
5. Carlo Pirola, Federico Galli, Carlo A. Rinaldini, Flavio Manenti, Massimo Milani, Luca Montorsi, Effects of humidified enriched air on combustion and emissions of a diesel engine, Renewable Energy 155 (2020) 569-577. https://doi.org/10.1016/j.renene.2020.03.155

6. Krystyna Bryś, Tadeusz Bryś, Marderos Ara Sayegh, Hanna Ojrzyńska, Characteristics of heat fluxes in subsurface shallow depth soil layer as a renewable thermal source for ground coupled heat pumps, Renewable Energy 146 (2020) 1846-1866.

https://doi.org/10.1016/j.renene.2019.07.101

7. Abdul Ghani Olabi, Montaser Mahmoud, Bassel Soudan, Tabbi Wilberforce, Mohamad Ramadan, Geothermal based hybrid energy systems, toward eco-friendly energy approaches, Renewable Energy 147 (2020) 2003-2012. https://doi.org/10.1016/j.renene.2019.09.140

8. M. Alfaki Mohamed Faroug, Dasari Narasimha Rao, Ravi Samikannu, Sampath Kumar Venkatachary, Karthikrajan Senthilnathan, Comparative analysis of controllers for stability enhancement for wind energy system with STATCOM in the grid connected environment, Renewable Energy 162 (2020) 2408-2442. https://doi.org/10.1016/j.renene.2020.06.044

9. M.C. Ndukwu, D. Onyenwigwe, F.I. Abam, A.B. Eke, C. Dirioha, Development of a low-cost wind-powered active solar dryer integrated with glycerol as thermal storage, Renewable Energy 154 (2020) 553-568. https://doi.org/10.1016/j.renene.2020.03.016

10. Mohammed Kamil, Khalid M. Ramadan, Abdul Ghani Olabi, Eman I. Al-Ali, Xiao Ma, Omar I. Awad, Economic, technical, and environmental viability of biodiesel blends derived from coffee waste, Renewable Energy 147 (2020) 1880-1894. https://doi.org/10.1016/j.renene.2019.09.147

11. Rafat Al Afif, S. Sean Anayah, Christoph Pfeifer, Batch pyrolysis of cotton stalks for evaluation of biochar energy potential, Renewable Energy 147 (2020) 2250-2258. https://doi.org/10.1016/j.renene.2019.09.146

12. Zhe Liu, Yi Zhao, Yuerong Zhou, Faming Guan, Modeling, simulation and test results analysis of tethered undersea kite based on bead model, Renewable Energy 154 (2020) 1314-1326. https://doi.org/10.1016/j.renene.2020.03.013

13. Seonghun Kim, Sang-Dae Kim, Seok Young Sohn, Evaluation of the wastewater generated during alkaline pretreatment of biomass for feasibility of recycling and reusing, Renewable Energy 155 (2020) 1156-1164. https://doi.org/10.1016/j.renene.2020.04.018

14. Po-Tsung Hsiao, Wan-Tun Hung, Yu-Cheng Chen, Liang-Kun Huang, Chih-Chou Chang, ChingFu Chen, Hao-Wei Chen, Ming-De Lu, Yu-Pin Lin, Yung-Liang Tung, Pilot operation and lifetime assessment for indoor light energy harvesting photovoltaics, Renewable Energy, 152 (2020) 67 -74, https://doi.org/10.1016/j.renene.2020.01.018. 